\title{
Suplementação Energética na Recria de Bezerras de Corte Mantidas em Pastagem de Inverno
}

\section{Adriana Frizzo', Marta Gomes da Rocha², João Restle ${ }^{3}$, Denise Baptaglin Montagner ${ }^{4}$, Fabiana Kellermann de Freitas ${ }^{5}$, Davi Teixeira dos Santos ${ }^{6}$}

\begin{abstract}
RESUMO - Este trabalho foi conduzido para se avaliar o efeito de níveis de suplementação energética no desempenho produtivo e reprodutivo de 64 bezerras de corte Charolês e suas cruzas com Nelore, mantidas em pastagem cultivada de aveia preta (Avena strigosa Schreb) mais azevém (Lolium multiflorum Lam.). Os tratamentos consistiram em suplementação equivalente a 0; 0,7 e 1,4 \% do peso vivo $(\mathrm{PV}) /$ dia de farelo de arroz integral associado à polpa cítrica na proporção de 1:1. O método de pastejo foi contínuo, com lotação variável, visando manter massa de forragem de $1500 \mathrm{~kg} / \mathrm{ha}$ de matéria seca (MS). Foram avaliados o ganho médio diário, carga animal, ganho de peso por área, condição corporal, área pélvica, peso à puberdade, idade à puberdade, altura da garupa e consumo estimado de MS. A suplementação proporcionou maior ganho médio diário, carga animal e ganho de peso vivo/ha. Bezerras alimentadas exclusivamente em pastagens tiveram menor condição corporal e apresentaram menor porcentagem de cio do que bezerras suplementadas. A percentagem de fêmeas que mostraram cio até os 16 meses de idade foi de 9,1; 68,7 e 70,6\%, respectivamente. Os níveis de suplementação não interferiram em área pélvica, peso à puberdade, idade à puberdade e altura de garupa. O consumo estimado de MS foi menor no nível 1,4\% do PV/dia.
\end{abstract}

Palavras-chave: aveia, azevém, farelo de arroz, polpa cítrica, produção animal, puberdade

\section{Energy Supplementation for Rearing of Beef Heifers Kept on Cool Season Pasture}

\begin{abstract}
This work was carried outo to evaluate the effect of levels of energetic supplementation in productive and reproductive performance of sixty-four Charolais heifers and their crosses with Nellore, mantained in cultivated pasture of black oat (Avena strigosa Schreb) plus Italian ryegrass (Lulium mulktiflorum Lam.). The treatments considered supplementation of $0 ; 0.7$ and $1.4 \%$ of the live weight (LW)/day of rice bran associated with citric pulp, in the proportion of 1:1. A continuous grazing system with variable stocking rate was used, to maintain $1500 \mathrm{~kg} / \mathrm{ha}$ of DM in herbage mass in all treatments. The following parameters were evaluated: average daily gain, stocking rate, live weight gain, body condition, pelvic area, weight at puberty and age at puberty, hip height and estimated intake of DM. The supplementation increased average daily gain, stocking rate and live weight gain. Heifers kept only on pasture had lower body conditions and showed lower heat percentage than heifers supplemented with 0.7 and $1.4 \%$ of LW/day with no differences (P>0.05) between the 0.7 and $1.4 \%$ levels. The percentage of heifers showing heat until 16 months of age was $9.1 ; 68.7$ and $70.6 \%$, respectively. The supplementations levels did not affect pelvic area, age at puberty and hip height. The estimated intake of DM was lower for the level of $1.4 \% \mathrm{LW} /$ day.
\end{abstract}

Key Words: oat, ryegrass, rice bran, citrus pulp, animal production, puberty

\section{Introdução}

A base da alimentação para a pecuária de corte no Rio Grande do Sul é o campo nativo, que apresenta deficiência sistemática na produção de forragem no inverno. Como conseqüência, observa-se idade avançada de acasalamento das fêmeas, baixas taxas de natalidade, baixos índices de repetição de cria e altas taxas de mortalidade de bezerros (Cachapuz, 1995). A utilização de pastagens cultivadas de estação fria é uma das alternativas existentes para amenizar o vazio forrageiro que ocorre no outono/inverno, sendo as espécies mais utilizadas para pastejo a aveia preta e o azevém, cultivadas de forma isolada ou em misturas. Estas pastagens apresentam elevado potencial para contribuir na produção, tanto animal como de forragem (Lupatini et al., 1998; Restle et al., 1999a; Restle et al., 2000).

O estudo e desenvolvimento de sistemas integrados viáveis de alimentação e manejo na recria de

1 Zoot. Ms. Aluna do curso de Doutorado da UFRGS. E.mail: adrianafrizzo@yahoo.com.br

2 Eng.-Agr. Dra . Profa ${ }^{-}$. Adjunta do Departamento de Zootecnia - UFSM. R. Tuiuti 1554/201, CEP 97015662, Centro, Santa Maria, RS.

E.mail: tata@pro.via-rs.com.br

3 Eng.-Agr. PhD. Prof. Titular do Departamento de Zootecnia - UFSM. E.mail: jorestle@ccr.ufsm.br

4 Zoot. Aluna do curso de Pós-Graduação em Zootecnia. Bolsista CNPq, UFSM. E.mail: demontagner@yahoo.com.br

5 Eng.-Agr. Aluna do curso de Pós-Graduação em Zootecnia, UFSM. E.mail: fkfreitas@mail.ufsm.br

6 Zoot. Aluno do curso de Pós-Graduação em Zootecnia. Bolsista CAPES, UFSM. E.mail: daviteixeira@hotmail.com 
bezerras, visando redução da idade de acasalamento são fundamentais na pecuária de corte no Brasil. O uso estratégico de suplementos pode produzir impacto global no sistema de produção ao acelerar o crescimento de fêmeas no período pós-desmama (Rocha, 1997).

Para o acasalamento de novilhas com um ano de idade, em situação de pastejo, devem ser atendidas as necessidades dos animais para atingir adequado crescimento e bom ganho de peso. A suplementação energética, neste caso, pode ser usada estrategicamente para corrigir as deficiências da forragem consumida e melhorar o desempenho animal (Pascoal et al., 1999). Além disso, pode permitir aumento na carga animal por área devido ao efeito de substituição que ocorre sobre o consumo de forragem. Sobre o uso de suplementação energética em pastagens de inverno, no entanto, são poucos os dados disponíveis (Assmann et al., 1999; Rocha et al., 2000).

No Rio Grande do Sul, a maioria das fêmeas bovinas, mantidas em condições de pastagem nativa, são acasaladas aos três anos, produzindo assim sua primeira cria somente aos quatro anos de idade. A idade e peso à puberdade, o tamanho adulto, condição corporal e a área pélvica constituem um conjunto de características importantes no estudo da redução da idade de acasalamento de novilhas (Rocha, 1997; Beretta \& Lobato, 1998).

Reduzir a idade do primeiro acasalamento para dois anos é fácil de ser atingido através do uso de pastagens cultivadas de inverno (Restle et al., 1999b). No entanto, reduzir a idade de acasalamento para 13,5 meses requer o uso de suplementação energética associada a pastagem (Vaz \& Restle, 2000).

O farelo de arroz integral é um suplemento energético abundante e de fácil obtenção no sul do país. A polpa cítrica é um subproduto que ocasionalmente pode ser adquirido a baixo custo e ser utilizado na alimentação de ruminantes com o objetivo de tornar o sistema mais econômico. A utilização da mistura de farelo de arroz integral e polpa cítrica é uma alternativa que também pode ser utilizada para adequar a relação $\mathrm{Ca}: \mathrm{P}$. Além disso, a polpa cítrica parece ter efeito menos negativo sobre o consumo de forragem que suplementos energéticos baseados em amido, podendo contribuir para o aumento no consumo total (Poppi \& McLennam, 1995).

É importante salientar que o critério técnico utilizado para decidir sobre a dieta a se utilizar durante o primeiro inverno deve basear-se nas taxas de ganho exigidas pelas fêmeas para atingir o peso adequado para a puberdade, antes da época de monta (Rocha, 1997).

Este trabalho foi conduzido com o objetivo de avaliar o potencial produtivo e reprodutivo de bezerras de corte, mantidas em pastagem de aveia e azevém, suplementadas com dois níveis de uma mistura de farelo de arroz e polpa cítrica.

\section{Material e Métodos}

O experimento foi realizado no período de maio a novembro de 1999. O solo da área experimental é classificado como ARGISSOLO VERMELHO Distrófico arênico (EMBRAPA, 1999) pertencente a unidade de mapeamento São Pedro. A área utilizada foi de 8,5 ha com nove divisões, mais uma área contígua de 8,5 ha, totalizando 17 ha.

Os tratamentos foram níveis de suplementação energética, sendo eles: 0; 0,7 e 1,4\% do PV/dia. O suplemento utilizado foi constituído de $50 \%$ de farelo de arroz integral e 50\% de polpa cítrica, sendo fornecido diariamente às $14 \mathrm{~h}$.

A massa de forragem da pastagem foi avaliada através da técnica de dupla amostragem (Wilm, 1944). Das amostras obtidas foi retirada uma composta, de cada área, para a determinação do teor de matéria seca (MS) e proteína bruta, pelo método micro Kjedahl (AOAC, 1984) e usando a metodologia de Tilley \& Terry (1963) para a determinação da digestibilidade in vitro da matéria seca e orgânica (DIVMS e DIVMO).

A simulação de pastejo foi realizada a cada 28 dias, quando, após observação do hábito de pastejo e preferência dos animais pelas espécies, foi coletada manualmente uma amostra de aproximadamente 0,400 $\mathrm{kg}$ de forragem/área experimental. As amostras foram pesadas e secas em estufa com ar forçado a $65^{\circ} \mathrm{C}$ por, no mínimo, 72 horas, para posteriormente serem realizadas as análises bromatológicas.

O sistema de pastejo utilizado foi o contínuo com lotação variável, utilizando-se a técnica put-and-take (Mott \& Lucas, 1952), visando manter a massa de forragem de $1500 \mathrm{~kg} / \mathrm{ha}$ de MS para todos os tratamentos. Em cada unidade experimental foram utilizados três animais testers (um do grupo genético Charolês (Ch), um $1 / 2$ Ch $1 / 2$ Nelore $(\mathrm{N})$ e o outro $3 / 4 \mathrm{Ch}$ $1 / 4 \mathrm{~N}$ ) e um número variável de reguladores, conforme a necessidade de ajuste da carga animal. Foram utilizadas 64 bezerras das raças Charolês, Nelore e suas cruzas, com sete meses de idade e peso médio inicial de $192 \mathrm{~kg}$. Os animais reguladores foram 
distribuídos nos tratamentos de acordo com o grupo genético, visando manter os grupos genéticos equilibrados em cada tratamento.

A semeadura foi realizada em $24 / 06 / 99$, com o pastejo sendo iniciado após 54 dias, quando a pastagem apresentava massa de forragem média de 893 $\mathrm{kg} / \mathrm{ha}$ de MS. As pesagens para a avaliação do ganho médio diário, carga animal e ganho de peso vivo/ha, foram feitas a cada 28 dias, com os animais sendo submetidos a jejum prévio de seis horas. Posteriormente era então realizado o ajuste da carga animal em cada potreiro. A diferença de peso dos animais testers entre as datas de pesagem, dividido pelo número de dias entre as pesagens, constituiu o ganho médio diário (GMD) dos testers em cada período experimental. A carga animal por período, expressa em $\mathrm{kg}$ de peso vivo/ha/dia, foi calculada pelo somatório do peso médio de cada animal multiplicado pelo número de dias que este permaneceu na pastagem, dividido pelo número de dias do período. $\mathrm{O}$ ganho de peso vivo/ha (GPV) foi obtido multiplicando o número de animais/dia/ha pelo ganho médio dos testers.

Para o cálculo da estimativa do consumo estimado de MS, foi subtraído da produção total de MS/ha a forragem disponível no final do período experimental e as perdas de forragem ocorridas ao longo do período de pastejo. Dividindo o consumo estimado de MS/ha pela carga animal média, obteve-se o consumo estimado de MS em \% do PV.

Para o cálculo da eficiência de utilização da MS, foi subtraído da produção total de MS/ha a massa de forragem no final do período experimental mais as perdas de forragem ocorridas durante o período de pastejo e dividido pelo ganho de peso vivo/ha.

A cada pesagem as fêmeas foram submetidas a uma avaliação subjetiva de sua condição corporal por dois avaliadores. Os critérios utilizados foram adaptados da classificação de Lowman et al. (1973), onde a condição varia de 1 (muito magra) a 5 (muito gorda).

Os dados experimentais foram coletados no período de 09/07 a 12/11, totalizando 124 dias de pastejo. Foi considerado um período de adaptação de 15 dias dos animais à área e ao suplemento.

A puberdade foi considerada como a manifestação do primeiro estro seguido por estros regulares a cada 21 dias. As observações diárias do estro iniciaram em 17/08/1999 e prolongaram-se até 07/02/ 2000. Após o final do ciclo da pastagem cultivada os animais permaneceram como rebanho único, sem suplementação, em campo nativo.

A medida de área pélvica foi tomada por ocasião das pesagens realizadas nos dias 10/09/99 e 07/02/00, sendo a área pélvica medida por via retal, com o auxílio do pelvímetro de Rice. No método descrito por Deutcher (1985) apud Fontana (1993), a largura ou medida horizontal é a maior distância entre o íleo direito e o esquerdo, na altura do tubérculo psoas. A altura é a distância vertical entre a sínfise do púbis e a base do corpo das vértebras sacrais. As medidas horizontais e verticais foram aferidas em centímetros e depois multiplicadas para ser obtida a estimativa da área pélvica (AP) em $\mathrm{cm}^{2}$.

A altura da garupa foi tomada com o auxílio de uma régua graduada em centímetros, onde o animal foi mantido imobilizado e com a linha dorsal reta. A medida foi tomada na altura da garupa no início e no final do experimento.

O delineamento experimental foi o inteiramente casualizado, com três repetições. Os dados coletados foram submetidos à análise de variância pelo GLM e análise de regressão, através do programa estatístico SAS (1990).

Os dados de ocorrência de estro foram submetidos a análise do $X^{2}$ (Qui-quadrado; Gomes, 1985).

\section{Resultados e Discussão}

Os percentuais médios de MS, PB e DIVMO das amostras obtidas por simulação de pastejo ao longo dos períodos avaliados encontram-se na Tabela 1. Não houve interação $(\mathrm{P}>0,05)$ entre tratamento e período de pastejo para estas variáveis. Não foi encontrada diferença $(\mathrm{P}>0,05)$ para $\% \mathrm{MS}, \% \mathrm{~PB}$ e \%DIVMO entre os níveis de suplementação. Houve diferença $(\mathrm{P}<0,05)$ para \%MS, \%PB e \%DIVMO entre os períodos de utilização da pastagem.

Observa-se que o teor de MS nos diferentes períodos apresentou aumento linear com o avanço do período de utilização da pastagem, onde a regressão linear permitiu estimar incrementos de 0,02 pontos percentuais na MS a cada dia de pastejo. Este comportamento está de acordo com a afirmação de Blaser (1990) de que há aumento percentual de MS com o avanço no estádio de desenvolvimento das plantas.

Na média dos tratamentos, a \% PB encontrada foi de $12,75 \%$, sendo suficiente para suprir as exigências de PB desta categoria para um ganho de $0,906 \mathrm{~kg} / \mathrm{dia}$, que é de 11,86\% (NRC, 1984). O teor de PB da 
Tabela 1 - Porcentagem de matéria seca (MS), proteína bruta (PB) e digestibilidade in vitro da matéria orgânica (DIVMO) da simulação de pastejo em aveia mais azevém sob pastejo contínuo com bezerras de corte submetidas a diferentes níveis de suplementação energética

Table 1 - Percentage of dry matter (DM), crude protein (CP) and "in vitro" organic matter digestibility (IVOMD) of hand plucking of oat plus Italian ryegrass under continuous grazing with beef heifers with different energetic supplementation level

\begin{tabular}{lccccc}
\hline Tratamento & \multicolumn{3}{c}{$\begin{array}{c}\text { Período } \\
\text { Period }\end{array}$} & $\begin{array}{c}\text { Média } \\
\text { Average }\end{array}$ \\
\cline { 2 - 5 } & $05 / 08-03 / 09$ & $03 / 09-01 / 10$ & $01 / 10-29 / 10$ & $29 / 10-12 / 11$ & \\
\hline MS (\%) & 16,22 & 17,83 & 19,43 & 19,05 & 18,13 \\
$D M(\%)$ & 16,37 & 13,16 & 10,74 & 10,47 & 12,75 \\
PB (\%) & 70,10 & 60,86 & 56,80 & 55,83 & 61,73 \\
CP (\%) & & & & & \\
DIVMO (\%) & & & & & \\
IVOMD (\%) & & &
\end{tabular}

$\% \mathrm{MS}=16,09+0,02 \mathrm{P}^{*}\left(\mathrm{P}<0,0012 ; \mathrm{R}^{2}=0,2692\right)$.

$\% \mathrm{~PB}=17,71-0,071 \mathrm{P}\left(\mathrm{P}<0,0001 ; \mathrm{R}^{2}=0,7470\right)$.

$\%$ DIVMO= 73,19-0,16P $\left(P<0,0001 ; R^{2}=0,6558\right)$.

${ }^{*} \mathrm{P}=$ dia de pastejo ( ${ }^{*} \mathrm{P}=$ days of grazing).

forragem da simulação de pastejo, nos períodos, apresentou comportamento linear decrescendo em $0,07 \%$ a cada dia de pastejo. À medida que a pastagem aproxima-se do final do seu ciclo de produção as espécies apresentam quantidade maior de colmos em relação a folhas, que é a parte da planta que apresenta maior teor de $\mathrm{N}$ e digestibilidade.

Foi observado comportamento linear na equação de regressão para \%DIVMO, sendo que esta decresceu 0,16 pontos percentuais para cada dia de pastejo. Isto nos mostra o decréscimo que ocorre na qualidade da pastagem à medida que vai avançando o seu ciclo de produção, e isto é de muita importância, pois a digestibilidade juntamente com o consumo voluntário afetam o consumo de energia, que é o principal fator limitante da produtividade animal.

Os dados de GMD são apresentados na Tabela 2. Houve diferença $(\mathrm{P}<0,05)$ para as médias dos trata mentos, não havendo interação $(\mathrm{P}>0,05)$ entre período e tratamento para a variável GMD.

A análise de regressão permite descrever comportamento quadrático para GMD entre períodos, sendo que foram observados aumentos gradativos no GMD até o terceiro período (03/09 a 01/10), ocorrendo

Tabela 2 - Ganho de peso médio diário (kg/animal) em aveia mais azevém sob pastejo contínuo com bezerras de corte submetidas a diferentes níveis de suplementação energética

Table 2 - Average daily gain (kg/animal) of oat plus Italian ryegrass under continuous grazing with beef heifers with different energetic supplementation levels

\begin{tabular}{|c|c|c|c|c|c|c|}
\hline \multirow[t]{2}{*}{$\begin{array}{l}\text { Tratamento } \\
\text { Treatment }\end{array}$} & \multicolumn{5}{|c|}{$\begin{array}{l}\text { Período } \\
\text { Period }\end{array}$} & \multirow[t]{2}{*}{$\begin{array}{l}\text { Média } \\
\text { Average }\end{array}$} \\
\hline & 09/07-05/08 & 05/08-03/09 & $03 / 09-01 / 10$ & $01 / 10-29 / 10$ & $29 / 10-12 / 11$ & \\
\hline & & & $\begin{array}{l}\text { GMD (kg/dia) } \\
L W G(k g / \text { day })\end{array}$ & & & \\
\hline $\begin{array}{l}\text { Sem suplementação } \\
\text { No supplement }\end{array}$ & 0,714 & 0,861 & 1,161 & 0,602 & 0,245 & $0,716^{\mathrm{b}}$ \\
\hline $\begin{array}{l}0,7 \% \text { PV } \\
0.7 \% L W\end{array}$ & 0,807 & 1,073 & 1,365 & 0,846 & 0,422 & $0,901^{\mathrm{a}}$ \\
\hline $\begin{array}{l}1,4 \% \mathrm{PV} \\
1.4 \% \mathrm{LW}\end{array}$ & 0,817 & 0,932 & 1,060 & 0,908 & 0,507 & $0,844^{\mathrm{ab}}$ \\
\hline $\begin{array}{l}\text { Média } 2 \\
\text { Average } \\
\end{array}$ & 0,779 & 0,955 & 1,195 & 0,785 & 0,391 & \\
\hline
\end{tabular}

R. Bras. Zootec., v.32, n.3, p.643-652, 2003 
decréscimo nos períodos posteriores.

Ao analisar a relação entre pastagem e suplemento é importante considerar que a pastagem reduz sua qualidade ao longo do período (Tabela 1), enquanto o suplemento mantinha valores constantes de PB $(7,10 \%)$ e DIVMO (76,25\%). A DIVMO do suplemento foi sempre superior quando comparada com as amostras de forragem da simulação de pastejo enquanto seu teor de PB sempre foi menor que o da forragem consumida. As exigências nutricionais de fêmeas com $240 \mathrm{~kg}$ de peso vivo para ganho de 0,906 $\mathrm{kg} / \mathrm{dia}$, são de $6,25 \mathrm{~kg}$ de MS, 11,86\% PB e 73,6\% NDT (NRC, 1984). É importante observar que a pastagem formada pela composição de aveia e azevém, durante seu ciclo de produção, consegue atender as exigências de $\mathrm{PB}$ dos animais. $\mathrm{O}$ uso de suplementos com valores de PB inferiores a esta exigência, como o suplemento utilizado, pode reduzir o ganho animal quando substitui grande parte do consumo de forragem, como no tratamento $1,4 \%$ do peso vivo, comparado com a utilização de menor quantidade de suplemento. No entanto, o conteúdo energético do suplemento, superior ao conteúdo energético da forragem, quando utilizado no nível de 0,7 do $\mathrm{PV}$, proporcionou ganho individual superior ao dos animais exclusivamente em pastagem.

As relações qualitativas forragem/suplemento variaram de acordo com o período e com a proporção que o suplemento representava da dieta do animal. Os GMD sempre foram maiores para os animais suplementados com relação aos não suplementados, caracterizando o efeito aditivo do suplemento. Foi exceção o período de setembro quando os animais conseguiram retirar da pastagem os nutrientes necessários para realizarem ganho maior que o proporcionado no tratamento $1,4 \%$ do PV. Provavelmente isto ocorreu em conseqüência do desbalanço nutricional causado pela maior participação na dieta do suplemento com reduzido teor de N. No período inicial de utilização da pastagem o suplemento, com 93,5\% de MS, certamente ocasionou maior consumo total de MS pelos animais devido ao elevado teor de água da pastagem nesta ocasião. A suplementação energética durante o período final do ciclo da pastagem proporcionou aumentos no GMD de 72,2 e 107\% para os níveis de 0,7 e 1,4\% do PV/dia, em relação ao não suplementado. A importância do maior aporte energético proveniente do suplemento é assim evidenciada nesta fase do ciclo da pastagem. Restle et al. (2000b) verificaram que a suplementação energética não afetou o ganho de peso dos animais na fase de crescimento da pastagem cultivada de inverno. Já na fase final do ciclo das pastagens cultivadas, o suplemento energético favoreceu o ganho de peso dos animais (Restle et al., 2001). Na média de todos os períodos, o GMD foi de 20,5 e 6,3\% superior para os níveis de 0,7 e 1,4\% do PV/dia em relação ao sem suplemento.

O consumo estimado de forragem, expresso em $\%$ do PV, foi maior no nível de $0,7 \%$ do PV/dia $(5,11)$ em relação ao sem suplemento $(4,8)$ e ao $1,4 \%$ do PV/ dia $(3,26)$. No nível de $0,7 \%$ do PV/dia ocorreu maior consumo devido ao efeito aditivo com estímulo proporcionado pelo suplemento. No nível de 1,4\% do PV/ dia houve diminuição no consumo de forragem devido ao efeito de substituição, no qual a redução no consumo de forragem é expressa como uma proporção da quantidade do suplemento consumido. $\mathrm{O}$ coeficiente de substituição da forragem pelo suplemento encontrado para este tratamento foi de 0,92. Quanto maior for o nível de suplementação, menor será o consumo de forragem, sendo que nestas circunstâncias, existe uma mudança na microflora ruminal, resultando em declínio das bactérias celulolíticas (Henning et al., 1980). É importante salientar que os valores estimados para o consumo, embora não correspondam ao verdadeiro consumo, em \% de PV, refletem a ação do suplemento sobre o consumo de forragem.

Segundo Reis et al. (1996), a diminuição no consumo de forragem por animais em pastejo é semelhante ao ocorrido com animais confinados, em resposta à suplementação energética, e está associada à progressiva diminuição no tempo de pastejo e tamanho do bocado, com o aumento do nível de suplementação.

Quando o consumo estimado de forragem é somado ao consumo de suplemento de 1,74 e $3,58 \mathrm{~kg}$ para os níveis de 0,7 e 1,4\% do PV/dia, obtêm-se consumos totais de MS de 4,8; 6,85 e 6,84 kg MS para os níveis de $0 ; 0,7$ e 1,4\% do PV/dia. Desta forma, a dieta dos animais no nível de 0,7 foi composta de 74,6 e $25,4 \%$ de forragem e suplemento, enquanto que no nível de 1,4\% do PV esta foi de 47,7 e 52,3\% de forragem e suplemento, respectivamente.

Os animais do tratamento sem suplementação não consumiram a quantidade necessária de MS estimada, enquanto o consumo total de MS obtido nos tratamentos suplementados foi o preconizado pelo NRC (1984). Com relação a PB, nos tratamentos suplementados, em função do nível de PB do suple- 
mento $(7,10 \%)$, não foi atingido o consumo preconizado pelo NRC (1984). O consumo ideal de PB para esta categoria e peso vivo é de $0,737 \mathrm{~kg} / \mathrm{dia}$ e os tratamentos com 0; 0,7 e 1,4\% do PV/dia forneceram, respectivamente, 0,796, 0,698 e 0,594 kg de PB. Este fato mostra a importância do nível de PB na forragem quando se pretende maiores ganhos individuais, principalmente quando se utiliza animais jovens. Esta categoria possui exigência elevada por estar em crescimento e, conseqüentemente, em fase de formação muscular onde a proteína entra como principal constituinte.

Os resultados obtidos permitem concluir que os animais deste experimento consumiram maior quantidade de MS que os de Soares (1999) e aos de Roso \& Restle (2000) trabalhando com a mesma categoria animal em pastagem de inverno sem suplementação.

A melhor eficiência de transformação da forragem consumida foi obtida no nível de suplementação com $1,4 \%$ do PV/dia $(8,26 \mathrm{~kg})$, seguida pelo sem suplemento $(11,80 \mathrm{~kg})$ e pelo $0,7 \%$ do PV/dia $(12,32$ $\mathrm{kg}$ ). Estes valores foram semelhantes aos encontrados por Roso \& Restle (2000), os quais usaram a mesma metodologia descrita no presente trabalho e superiores aos de Restle et al. (1998) e Restle et al. (1999a), que não consideraram perdas por pisoteio e senescência para o cálculo.

Nos tratamentos com 0,7 e 1,4\% do PV/dia foram utilizados 9,26 e 11,60 kg de suplemento para cada $\mathrm{kg}$ de ganho/ha adicional em relação ao tratamento sem suplemento. Assmann et al. (1999) utilizou 4,8 kg de milho/kg de ganho e Rocha et al. (2000) encontraram em média 7,4 kg de sorgo moído/kg de ganho.

$\mathrm{O}$ tratamento mais eficiente, quando considerouse o consumo total (forragem mais suplemento) foi o sem suplementação (11,80 kg/kg de ganho), seguido pelo nível de $1,4 \%$ do PV/dia (12,64 kg/kg de ganho) e pelo $0,7 \%$ do $\mathrm{PV} / \mathrm{dia}(14,41 \mathrm{~kg} / \mathrm{kg}$ de ganho).

Os resultados de carga animal e ganho de peso vivo por área (GPV/ha) encontram-se na Tabela 3. O GPV por área está diretamente relacionado ao ganho médio diário e ao número de animais/dia/ha no período, sendo que estes estão relacionados com a qualidade e produção da forragem.

A suplementação dos animais proporcionou aumentos de carga animal de $26,6 \%$ e $65,3 \%$ para os níveis de 0,7 e 1,4 \% do PV/dia (Tabela 3). Valores semelhantes foram obtidos por Assmann et al. (1999) que, utilizando milho macerado, obtiveram cargas médias de 1390,1 e 1458,1 kg de PV/ha para os níveis
Tabela 3 - Carga animal (CA) e ganho de PV/ha em aveia e azevém sob pastejo contínuo com bezerras de corte submetidas a diferentes níveis de suplementação energética

Table 3 - Stocking rate (SR) and live weight gain ( $L W /$ ha) of oat plus Italian ryegrass under continuous grazing with beef heifers with different energetic supplementation levels

Parâmetro Níveis de suplementação (\%PV/dia)

\begin{tabular}{|c|c|c|c|}
\hline & \multicolumn{3}{|c|}{ Supplementation (\%LW/day) } \\
\hline & 0 & 0,7 & 1,4 \\
\hline $\begin{array}{l}\text { CA (kg de PV/ha })^{1} \\
S R(L W / h a)\end{array}$ & $1065^{\mathrm{c}}$ & $1349^{b}$ & $1761^{a}$ \\
\hline $\begin{array}{l}\text { Ganho PV (kg/ha })^{2} \\
L W \text { Gain }(L W / h a)\end{array}$ & 433,3 & 559,3 & 696,4 \\
\hline
\end{tabular}

$1 \longdiv { \text { Valores seguidos por letras diferentes na mesma linha diferem } }$ $(\mathrm{P}<0,05)$ pelo teste " $\mathrm{t}$ ".

2 Ganho PV= 86,29+37,58NS* $\left(P<0,014 ; R^{2}=0,1308\right)$.

* NS = nível de suplementação.

1 Values followed by different letters in the same line differ $(P<0,05)$ by " $t$ " test.

$N S=$ level of supplementation.

de suplementação de 0 e $0,5 \%$ do PV.

No final do ciclo da pastagem, as maiores cargas foram observadas no tratamento com $1,4 \%$ do PV/ dia, sendo que os tratamentos com $0,7 \%$ do PV/dia e sem suplementação mantiveram cargas semelhantes, evidenciando assim o maior efeito do nível de suplementação sobre o aumento de carga.

Observa-se que os GPV/ha obtidos foram superiores em $29,0 \%$ e $60,7 \%$ para os níveis de 0,7 e 1,4 $\%$ do PV/dia, respectivamente, em relação ao sem suplemento. Estes valores se ajustam a uma equação de regressão linear em que a cada $0,1 \%$ de suplemento fornecido promove aumento de $37,58 \mathrm{~kg}$ no ganho/ ha de PV. Valores superiores foram encontrados por Assmann et al. (1999) que obtiveram uma produção de 651,5; 809,9 e 789,4 $\mathrm{kg}$ de PV/ha para $0 ; 0,5$ e 1,0 $\%$ PV/dia, respectivamente. Roso \& Restle (2000) utilizando a mesma categoria animal, exclusivamente em pastejo, obtiveram ganhos que variaram de 726,3 a $802,7 \mathrm{~kg} / \mathrm{ha}$ de PV, sendo que estes valores estão relacionados com um maior número de dias de pastejo.

$\mathrm{O}$ inicio da atividade reprodutiva nas fêmeas bovinas é de extrema importância e tem influencia no desempenho do rebanho de cria. Estudos sobre a puberdade mostram que o aparecimento do primeiro cio é devido a genética, idade, peso, condição corporal, local e ambiente (Wiltbank et al., 1966; Short \& Bellows, 1971).

No início do período experimental, o peso médio das bezerras foi de $192 \mathrm{~kg}$, a condição corporal foi de 
3,4 pontos e a altura tomada na garupa foi de 103,1 $\mathrm{cm}$. No final do experimento (12/11) não foram observadas diferenças $(\mathrm{P}>0,05)$ para peso, área pélvica e altura dos animais entre os tratamentos (Tabela 4).

Beretta \& Lobato (1998), avaliando diferentes sistemas de alimentação, não encontraram diferença $(\mathrm{P}>0,05)$ para $\mathrm{PV}$ e altura de garupa para novilhas em relação aos sistemas alimentares utilizados, sendo estes de 220,5 e 108,6 cm. Observa-se na Tabela 4 que os valores de área pélvica estão abaixo dos considerados ideais, 140 a $170 \mathrm{~cm}^{2}$ (Brinks, 1990), para novilhas com um ano de idade. Também são inferiores aos valores médios encontrados por Rocha (1997) e Beretta \& Lobato (1998) que avaliando animais da mesma categoria observaram 144 e $154 \mathrm{~cm}^{2}$. Medidas corporais como área pélvica devem ser consideradas em sistemas que visem o acasalamento aos 14-15 meses de idade, onde um dos principais problemas é a distocia (Fleck et al., 1980).

Os dados referentes a idade em dias, peso em $\mathrm{kg}$ ao primeiro estro, condição corporal e percentagem de manifestação de estro encontram-se na Tabela 5.

$\mathrm{O}$ conhecimento dos fatores que determinam o aparecimento da puberdade é de grande importância quando se pretende acasalar novilhas precocemente. Em regimes de produção intensivos se torna imprescindível acelerar o começo da vida reprodutiva dos animais. Assim, para obter a primeira parição aos dois anos de idade é preciso entourar as novilhas com idade média de 14-15 meses. Portanto, é importante que estes animais, nessa idade, tenham peso adequa- do, condição corporal e que estejam ciclando a cada 20-21 dias.

Não foram observadas diferenças $(\mathrm{P}>0,05)$ para peso e idade à puberdade entre os tratamentos. Conforme Lobato (1999), quando atendidas as exigências nutricionais pós-desmama, a maioria das novilhas reduzem a idade à puberdade e a idade ao primeiro serviço, o que também foi observado neste trabalho.

Rocha (1997), trabalhando com fêmeas Hereford e cruzas com Nelore em diferentes sistemas alimentares na pós-desmama, observou que o primeiro cio foi manifestado aos 439 dias com o animal pesando $263 \mathrm{~kg}$. Restle et al. (1999b) avaliando o desempenho reprodutivo de fêmeas das raças Charolês, Nelore e suas cruzas recíprocas, em um sistema de produção de dois anos, encontram idade e peso à puberdade de $326 \mathrm{~kg}$ e 689 dias para novilhas puras e $346 \mathrm{~kg}$ e 600 dias para novilhas cruzas. Beretta \& Lobato (1998) observaram que novilhas cruzas Hereford e Aberdeen Angus com 14 meses, apresentaram atividade cíclica com $254 \mathrm{~kg}$ e CC de 3,10 pontos.

A correlação entre idade e peso à puberdade apresentou um coeficiente de $0,98(\mathrm{P}<0,0001)$, evidenciando que bezerras mais tardias também foram as mais pesadas na puberdade. O coeficiente de correlação encontrado é superior ao relatado por outros trabalhos como Arije \& Wiltbank (1971), Rocha (1997) e Restle et al. (1999b).

Foi observada diferença $(\mathrm{P}<0,05)$ para $\mathrm{CC}$ entre tratamentos, sendo que os animais suplementados apresentaram as maiores $\mathrm{CC}$, sem diferir entre si

Tabela 4 - Peso vivo (PV) inicial e final, área pélvica (AP) e altura da garupa inicial e final de bezerras de corte em aveia e azevém sob diferentes níveis de suplementação energética

Table 4 - Initial and final live weight $(L W)$, pelvic area $(P A)$ and initial and final height of beef heifers heap on oat plus Italian ryegrass with different energetic supplementation levels

\begin{tabular}{|c|c|c|c|c|c|}
\hline \multirow[t]{2}{*}{$\begin{array}{l}\text { Tratamento } \\
\text { Treatment }\end{array}$} & \multicolumn{2}{|c|}{$\begin{array}{l}\text { PV (kg) } \\
L W(k g)\end{array}$} & \multirow[t]{2}{*}{$\begin{array}{l}\text { AP }\left(\mathrm{cm}^{2}\right) \\
P A\left(\mathrm{~cm}^{2}\right)\end{array}$} & \multicolumn{2}{|c|}{$\begin{array}{l}\text { Altura }(\mathrm{cm}) \\
\text { Height }(\mathrm{cm})\end{array}$} \\
\hline & $\begin{array}{c}\text { Inicial } \\
\text { Initial }\end{array}$ & $\begin{array}{l}\text { Final } \\
\text { Final }\end{array}$ & & $\begin{array}{c}\text { Inicial } \\
\text { Initial }\end{array}$ & $\begin{array}{c}\text { Final } \\
\text { Final }\end{array}$ \\
\hline $\begin{array}{l}\text { Sem suplementação } \\
\text { No supplement }\end{array}$ & 168 & 267 & 81,9 & 99,6 & 110,2 \\
\hline $\begin{array}{l}0,7 \% \text { PV } \\
0.7 \% L W\end{array}$ & 203 & 331 & 101,9 & 104,6 & 115,2 \\
\hline $\begin{array}{l}1,4 \% \mathrm{PV} \\
1.4 \% \mathrm{LW}\end{array}$ & 205 & 323 & 86,3 & 105,2 & 113,6 \\
\hline $\begin{array}{l}\text { Média } \\
\text { Average }\end{array}$ & 192 & 307 & 90,0 & 103,1 & 113,0 \\
\hline
\end{tabular}

$\mathrm{P}>0,05$. 
Tabela 5 - Valores médios de idade (dias) e peso vivo (PV,kg) na puberdade, condição corporal (CC, 1-5) e freqüência de manifestação de estro de bezerras de corte em aveia e azevém sob diferentes níveis de suplementação energética

Table 5 - $\quad$ Average age (days) and weight (W) at puberty, body condition (1-5) and rate of heat of heifers heap on oat plus Italian ryegrass with different energetic supplementation levels

\begin{tabular}{|c|c|c|c|c|}
\hline $\begin{array}{l}\text { Tratamento } \\
\text { Treatments }\end{array}$ & $\begin{array}{c}\text { Idade (dias) } \\
\text { Age (days) }\end{array}$ & $\begin{array}{l}\text { PV (kg) } \\
L W(k g)\end{array}$ & $\begin{array}{l}\mathrm{CC}^{1}(1-5) \\
B C(1-5) \\
\end{array}$ & $\begin{array}{c}\text { Estro } *(\%) \\
\text { Heat }(\%)\end{array}$ \\
\hline $\begin{array}{l}\text { Sem suplementação } \\
\text { No supplement }\end{array}$ & 280 & 270 & $3,6^{b * *}$ & $9,1^{\mathrm{b}}$ \\
\hline $\begin{array}{l}0,7 \% \text { PV } \\
0.7 \% L W\end{array}$ & 257 & 261 & $3,9^{\mathrm{a}}$ & $68,7^{\mathrm{a}}$ \\
\hline $\begin{array}{l}1,4 \% \mathrm{PV} \\
1.4 \% \mathrm{LW}\end{array}$ & 254 & 251 & $3,9^{\mathrm{a}}$ & $70,6^{\mathrm{a}}$ \\
\hline $\begin{array}{l}\text { Média } \\
\text { Average } \\
\end{array}$ & 264 & 261 & 3,8 & 49,5 \\
\hline
\end{tabular}

$(\mathrm{P}>0,05)$ (Tabela 5). Beretta \& Lobato (1998) obtiveram valores de CC no início do acasalamento de 2,54 a 3,01 para os diferentes sistemas de alimentação no pós-desmame, sendo estes inferiores aos obtidos no presente trabalho. Também Rocha (1997), trabalhando com sistemas alimentares pós-desmame, obteve valores de CC entre 3,68 a 3,81 no início do acasalamento. Segundo Restle (1977) e Lemenager et al. (1980), a condição corporal reflete as reservas energéticas, sendo que estas quando consideradas boas, serão refletidas na taxa de prenhez das fêmeas.

A flutuação na condição corporal é mais confiável que as flutuações de PV para avaliar o estado nutricional de um animal (Vizcarra, 1989). Em estudos realizados com alimentação de inverno geralmente observa-se que a CC decresce proporcionalmente mais que o PV, o que implica em maior perda de energia em relação ao peso (Bartley et al., 1984; Ferrel \& Jenkins, 1984).

A importância da CC para os sistema intensivos de produção pode ser observada pelos valores dos coeficientes de correlação desta variável com a porcentagem de cio $(0,98 \mathrm{P}<0,0001)$, com o peso à puberdade $(0,96 \mathrm{P}<0,0001)$ e idade à puberdade $(0,96 \mathrm{P}<0,0001)$.

Os animais suplementados não diferiram entre si $(\mathrm{P}>0,05)$ na porcentagem de manifestação de estros, sendo superiores $(\mathrm{P}<0,05)$ aos não suplementados. A manifestação de cio aumentou linearmente com os níveis de suplementação, conforme observado na Tabela 5. Os valores encontrados para porcentagem de estro foram de 9,$1 ; 68,7$ e 70,6\% para os tratamentos com 0; 0,7 e 1,4\% do PV/dia. Short \& Bellows (1971) também observaram aumentos na porcentagem de manifestação de cio, quando os níveis de nutrição foram crescentes durante o período de préacasalamento.

Observa-se que animais suplementados com 0,7 e $1,4 \%$ do PV/dia apresentaram 54,9 e $75,8 \%$, mais estros que os animais não suplementados. Os percentuais de estros obtidos neste trabalho nos tratamentos suplementados, 69,6\% em média, são superiores à média de 49,5\% para diferentes sistemas alimentares na pós-desmama em novilhas de mesma idade (Rocha, 1997).

A média de estros para todos os tratamentos $(49,5 \%)$ do presente trabalho é superior aos resultados obtidos por Restle et al. (1999b) que observaram médias de 7,2 e 39,6\% de manifestação de estros aos 12 e 18 meses em fêmeas mantidas em pastagem cultivada do desmame até os doze meses, e após o período de verão em campo nativo sem a utilização da suplementação até os 18 meses. Vaz \& Restle (2000) relataram percentagem média de prenhez de $62,5 \%$ em fêmeas que receberam diferentes níveis de suplementação durante o primeiro acasalamento, dos 13,5 aos 16,5 meses de idade.

A correlação entre peso e \% de cio mostrou um coeficiente de $0,97(\mathrm{P}<0,001)$ indicando que quanto maior o peso das fêmeas, maior é a manifestação de cio. Também foi encontrada correlação positiva para idade e porcentagem de cio, de 0,98 $(\mathrm{P}<0,001)$. 


\section{Conclusões}

A suplementação energética mostra efeito aditivo e substitutivo em pastagem cultivada de inverno, aumentando o GMD e a carga animal.

O ganho de peso vivo/ha em pastagem cultivada aumenta de forma linear com os níveis de suplementação até $1,4 \%$ do PV/dia.

O maior impacto da suplementação energética na carga animal em pastagem cultivada de inverno ocorre por ocasião do final do ciclo das forrageiras.

A suplementação energética para bezerras mantidas em pastagem cultivada de inverno aumenta significativamente a ocorrência de estros e a condição corporal, sendo recomendada para sistemas de acasalamento de fêmeas de corte com um ano de idade.

A suplementação energética em pastagens cultivadas de inverno não interfere no peso e idade à puberdade, área pélvica e altura de garupa em novilhas de corte.

\section{Literatura Citada}

ARIJE, G.F.; WILTBANK, J.N. Age and weight at puberty in Hereford heifers. Journal of Animal Science, v.33, n.2, p.401-406, 1971.

ASSMANN, A.L.; ASSMANN, T.S.; MORAES, A., et al. Efeito de diferentes níveis de suplementação com milho no ganho de peso de novilhos em pastejo. In: REUNIÃO ANUAL SOCIEDADE BRASILEIRA DE ZOOTECNIA, 36, 1999, Porto Alegre. Anais... Porto Alegre: Sociedade Brasileira de Zootecnia/Gnosis, [1999]. CD-ROOM. Forragicultura.

ASSOCIATION OF OFFICIAL ANALYTICAL CHEMISTS AOAC. Official methods of analysis. 14.ed. Washington, D.C.: 1984. 1141p.

BARTLEY, S.J.; MALES, J.R.; PRESTON, R.L. Effect of energy intake on the postpartum interval in beef calves and the adequacy of the cows milk production for calve growth. Journal of Animal Science, v.58, n.5, 1984.

BERETTA, V.; LOBATO, J.F.P. Sistema "um ano" de produção de carne: avaliação de estratégias alternativas de alimentação hibernal de novilhas de reposição. Revista Brasileira de Zootecnia, v.27, n.1, p.157-163, 1998.

BLASER, R.E. Manejo do complexo pastagem-animal para avaliação de plantas e desenvolvimento de sistemas de produção de forragens. In: PASTAGENS: FUNDAMENTOS DA EXPLORAÇÃO RACIONAL, 2., 1990, Piracicaba.Anais... Piracicaba: Fundação de Estudos Agrários “Luiz de Queiroz”, 1990. p.157-205.

BRINKS, J.S. Genetic influences on reproductive performance of two-year-old beef females. In: BEEF Research Progress Report. Colorado: Colorado State University, 1990. p. 1-11.

CACHAPUZ, J.M. da S. O panorama setorial da bovinocultura de corte gaúcha no processo de integração de MERCOSUL. 2.ed. Porto Alegre: EMATER, 1995. 68p. (Realidade Rural, 7)
EMPRESA BRASILEIRA DE PESQUISA E AGROPECUÁRIA EMBRAPA. Centro Nacional de Pesquisa de Solos. Sistema brasileiro de classificação de solos. Brasília:EMBRAPA. Rio de Janeiro, 1999. 412p.

FERREL, C.L.; JENKINS, G. Energy utilization by nature no pregnant, non lactating cows of different types.Journal of Animal Science, v.58, p.234-24, 1984.

FLECK, A.T.; SCHALLES, R.R.; KIRACOFE, G.H. Effect of growth rate thought 30 months on reproductive performance of beef heifers. Journal of Animal Science, v.51, n.4, p.816-821, 1980.

FONTANA, P.M.F. Distocia em novilhas Hereford com parição aos 24 meses de idade. Pelotas: Universidade Federal de Pelotas, 1993. 96p. Dissertação (Mestrado em Zootecnia) - Universidade Federal de Pelotas, 1993.

GOMES, F.P. Curso de estatística experimental.Piracicaba: Ed. Nobel, 1985. 466p.

HENNING, P.A.; LINDEN, Y.; MATTHORPE, M.C. et al. Factors affecting the intake and digestion of roughage by sheep fed maize straw supplemented with maize grain. Journal of Agricultural Science, v.94, n.2, p.565-571, 1980.

LEMENAGER, R.P.; SMITH, W.H.; MARTIN, T.G. et al. Effects of winter and summer energy levels on heifers growth and reproductive performance.Journal of Animal Science, v.51, n.4, p.837-842, 1980.

LOBATO, J.F.P. Considerações efetivas sobre seleção, produção e manejo para maior produtividade dos rebanhos de cria. In: LOBATO, J.F.P.; BARCELLOS, J.O.J.; KESSLER, A.M. (Eds.). Produção de bovinos de corte.Porto Alegre: EDIPURCS, p.235-286. 1999.

LOWMAN, B.G.; SCOTT, N.; SOMERVILLE, S. Condition scoring beef cattle. Edinburgh: East of Scotland College of Agriculture, 1973. 8p. (Bulletin, 6).

LUPATINI, G.C.; RESTLE, J.; CERETTA, M. Avaliação da mistura de aveia preta e azevém sob pastejo submetida a níveis de nitrogênio. Pesquisa Agropecuária Brasileira, v.33, n.11, p.1939-1943, 1998.

MOTT, G.O.; LUCAS, H.L. The design conduct and interpretation of grazing trials on cultivated and improved pastures. In: INTERNATIONAL GRASSLAND CONGRESS, 6., 1952, Pennsylvania. Proceedings... Pennsylvania: State College Press, 1952. p.1380-1395.

NATIONAL RESEARCH COUNCIL - NRC. Necesidades nutritivas del ganado vacuno. 3.ed. Buenos Aires: Hemisferio Sur, 1984. p.104.

PASCOAL, L.L.; BRONDANI, I.L.; BERNARDES, R.A.C. Avaliação de dietas para desmame, suplementação e confinamento. In: CONFINAMENTO, PASTAGENS E SUPLEMENTAÇÃO PARA PRODUÇÃO DE BOVINOS DE CORTE, 1999, Santa Maria. Anais... Santa Maria: Universidade Federal de Santa Maria, 1999. p.125-146.

POPPI, D.P.; McLENNAN, S.R. Protein and energy utilization by ruminants at pasture.Journal of Animal Science, v.73, n.1, p.278-290, 1995.

REIS, R.A.; RODRIGUES, L.R.A.; PEREIRA, J.R.A. A suplementação como estratégia de manejo da pastagem. In: PEIXOTO, A. M.; MORA, J.C.; FARIA, V.P. (Eds.) Produção de bovinos a pasto. Piracicaba: Fundação de Estudos Agrários "Luiz de Queiroz", 1996. p.123-150.

RESTLE, J. Estado corporal e desempenho reprodutivo em vacas de corte. In: REUNIÃO ANUAL DA SOCIEDADE BRASILEIRA DE ZOOTECNIA, 1977, 14., Recife. Anais... 
Recife, Sociedade Brasileira de Zootecnia, 1977. p.107.

RESTLE, J.; LUPATINI, G.C.; ROSO, C. Eficiência e desempenho de categorias de bovinos de corte em pastagem cultivada. Revista Brasileira de Zootecnia, v.27, n.2, p.397-404, 1998.

RESTLE, J.; ROSO, C.; SOARES, A.B. Produção animal e retorno econômico em misturas de gramíneas anuais de estação fria. Revista Brasileira de Zootecnia, v.28, n.2, p.235-243, 1999a.

RESTLE, J.; POLLI, V.A.; SENNA, D.B. Efeito de grupo genético e heterose na idade à puberdade e desempenho reprodutivo de novilhas de corte. Pesquisa Agropecuária Brasileira, v.34, n.4, p.701-707, 1999 b.

RESTLE, J.; ROSO, C.; SOARES, A.B. Produtividade animal e retorno econômico em pastagem de aveia preta mais azevém adubada com fontes de nitrogênio em cobertura. Revista Brasileira de Zootecnia, v.29, n.2, p.357-364, 2000a.

RESTLE, J.; ROSO, C.; OLIVEIRA, A.N. et al. Suplementação energética para vacas de descarte em terminação em pastagem cultivada de inverno sob pastejo horário. In: REUNIÃO ANUAL DA SOCIEDADE BRASILEIRA DE ZOOTECNIA, 37., Viçosa. Anais...Viçosa: Sociedade Brasileira de Zootecnia/Gnosis, [2000b]. CD-ROOM. Nutrição de Ruminantes.

RESTLE, J.; VAZ, F.N.; ROSO, C. et al. Desempenho e características de carcaça de vacas de diferentes grupos genéticos submetidas a níveis de suplementação energética em pastagem cultivada de estação fria. Revista Brasileira de Zootecnia, n.6, p.1813-1823, 2001.

ROCHA, M.G. Desenvolvimento e características de produção de novilhas de corte primíparas aos dois anos de idade.Porto Alegre: Universidade Federal do Rio Grande do Sul, 1997. 247p. Tese (Doutorado em AgronomiaZootecnia) - Universidade Federal do Rio Grande do Sul, 1997.

ROCHA, M.G.; RESTLE, J.; FARINATTI, L.H. et al. Efeito da suplementação energética sobre a produção animal em pastagem cultivada de inverno. In: REUNIÃO ANUAL DA SOCIEDADE BRASILEIRA DE ZOOTECNIA, 37., 2000, Viçosa. Anais...Viçosa: Sociedade Brasileira de Zootecnia/ Gnosis, [2000]. CD-ROM. Forragicultura.
ROSO, C.; RESTLE, J. Aveia preta, triticale e centeio em mistura com azevém. 2. Produtividade animal e retorno econômico. Revista Brasileira de Zootecnia, v.29, n.1, p.85-93, 2000. SAS INSTITUTELanguage reference. Version 6, Cary: 1990. $1042 p$.

SHORT, R.E.; BELLOWS, R.A. Relationship among weigh gains, age at puberty and reproductive performance in heifers. Journal of Animal Science, v.32, n.5, p. 1964-1970, 1971.

SOARES, A.B. Nível de adubação nitrogenada sobre a produtividade animal e da pastagem de triticale (xtriticosecale) e azevém (Lolium multiflorum). Santa Maria: Universidade Federal de Santa Maria, 1999. 189p. Dissertação (Mestrado em Zootecnia) - Universidade Federal de Santa Maria, 1999.

TILLEY, J.M.A.; TERRY, R.A.A. Two stage technique for the "in vitro" digestion of forage crops. Journal of British Grassland Society, v.18, n.2, p. 104-111, 1963.

VAZ, R.Z.; RESTLE, J. Níveis de suplementação para novilhas durante o primeiro período reprodutivo dos 14 aos 17 meses. II- Desempenho reprodutivo. In: REUNIÃO ANUAL DA SOCIEDADE BRASILEIRA DE ZOOTECNIA, 37., 2000, Viçosa. Anais...Viçosa: Sociedade Brasileira de Zootecnia/ Gnosis, [2000]. CD-ROOM. Nutrição de ruminantes.

VIZCARRA, J.A. Algunas estrategias para el manejo del rodeo de cria. In: JORNADA SOBRE ESTRATEGIAS DE SUPLEMENTACION DE PASTURAS EN SISTEMAS INTENSIVOS. MGAP -DDGGTT - CIAAB, La Estanzuela, julio. 1989.

WILM, H.G.; COSTELLO, D.F.; KLIPPLE, G.E. Estimating forage yield by the double-sampling methods. Journal of American Society of Agronomy, v.36, p.194-203, 1944.

WILTBANK, J.N.; GREGORY, K.E.; SWIGER, L.A. et al. Effects of heterosis on age and weight at puberty in beef heifers. Journal of Animal Science, v.25, n.5, p.744-751, 1966.

Recebido em: 17/05/01

Aceito em: 02/10/02 